Brit.J. Ophthal. (1962) 46, 51.

\title{
UNIOCULAR APLASIA OF THE OPTIC NERVE*
}

\author{
BY
}

\author{
FROMA SOMERVILLE \\ London
}

\begin{abstract}
APLASIA of the optic nerve occurring as an isolated abnormality in an eye of normal external appearance is rare. It is seen more frequently in association with more obvious developmental anomalies of the eye and its adnexa, and with such gross defects as anencephaly. When both eyes are affected by aplasia of the optic nerves alone, grossly defective vision is apparent early in life; but when the condition is uniocular it may present as a diagnostic problem at a later age. There may be a history of poor vision from birth, and of an accompanying squint since infancy in the affected eye, and ophthalmoscopy reveals an abnormally small disc. There is no appreciable refractive error, and the condition is not familial. Details of a uniocular case presenting in middle age with these typical clinical features are therefore considered worthy of record.
\end{abstract}

\section{Case Report}

A married Cypriot woman aged 50 had been admitted to hospital with symptoms resulting from minor spondylosis of the cervical spine and tuberculous cervical lymphadenitis. The left eye was noted to be blind and convergent, and the patient was referred for diagnosis for this reason.

She had evidently never been able to see with the left eye, in which there had been a convergent squint for as long as she could remember. There was no family history of ocular abnormality.

Examination.-Both eyes were of normal size and appearance, but there was a left convergent squint of about $10^{\circ}$. The unaided visual acuity in the right eye was $6 / 6$, whereas there was no perception of light in the left. Retinoscopy revealed no appreciable refractive error in either eye. No abnormality was found in the right eye, the visual field being full and colour vision normal. The right pupil did not react consensually, whereas the left pupil reacted consensually but not directly. The left ocular media were clear and the left fundus was normal in appearance except for the optic disc, which was about twothirds of the normal diameter and physiologically cupped (Figs 1 and 2, overleaf).

$X$ ray of the orbits showed them to be of the same size, but the left optic foramen was smaller than the right (Fig. 3, overleaf).

* Received for publication February 10, 1961 


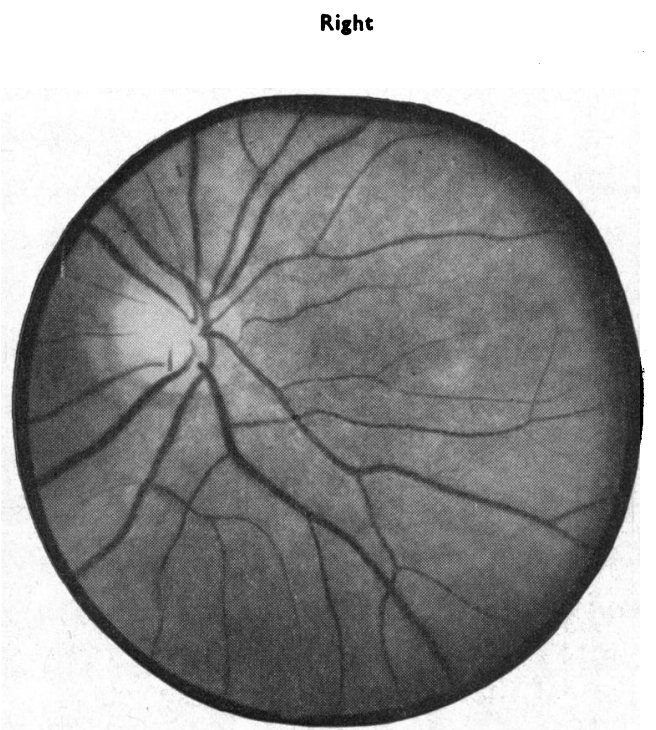

Fig. 1.-Right optic disc.

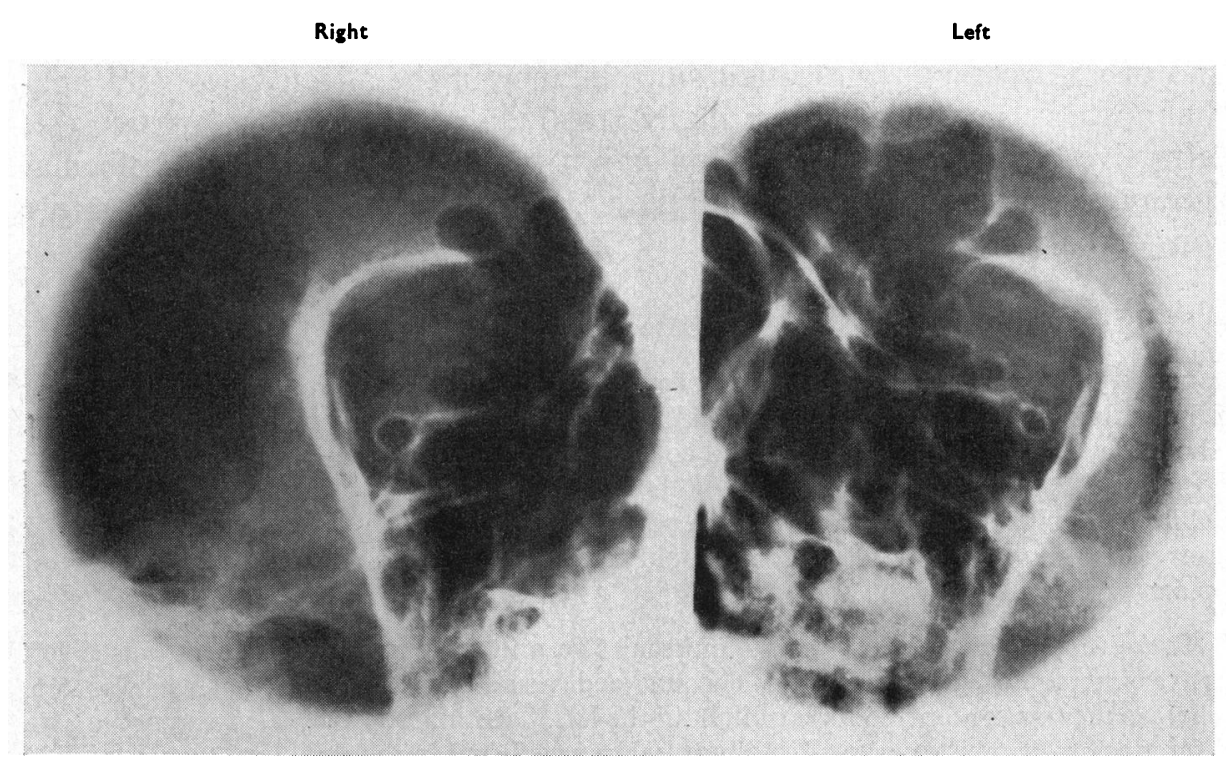

Fig. 3. Skiagrams of right and left optic foramina.

\section{Discussion}

Only a few cases of aplasia of the optic nerve occurring as an isolated abnormality have been reported; five of these were uniocular and seven binocular.

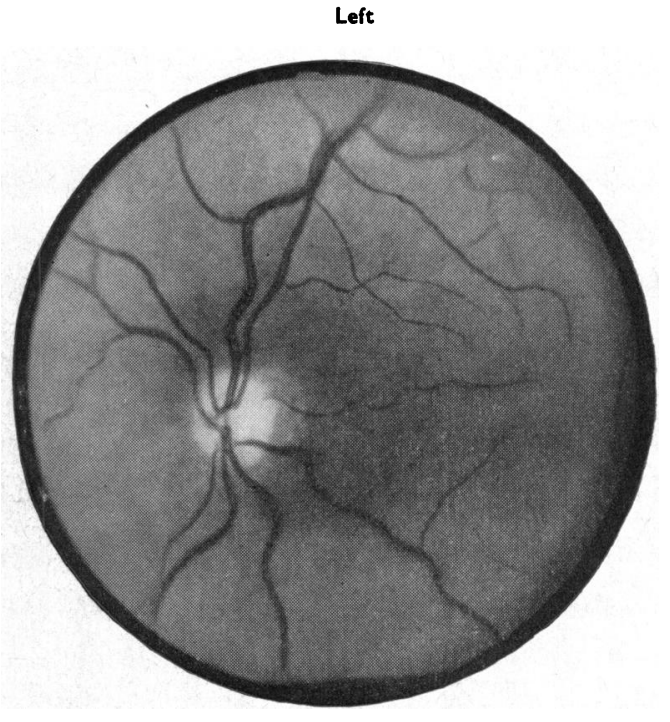

Fig. 2.-Left optic disc and macular area. 
Uniocular Cases.-Uniocular aplasia in otherwise normal eyes has been described by Cords (1923), Velhagen (1930), Smith (1954) who reported two cases, and Walsh (1957).

The essential clinical features of the condition were seen in these cases, as in the case described above. The eye appeared externally to be normal, but vision had been greatly reduced or absent from birth, and the fundus picture showed as its chief or only abnormality an optic disc which was greatly reduced in size without marked pallor. There was a convergent squint in the affected eye in all cases except one in which the eye had diverged. Radiological examination of the optic foramina was reported by Velhagen (1930) and the foramen of the affected side was found to be reduced in diameter.

Binocular Cases.-Bilateral aplasia in otherwise normal eyes has been reported by Schwarz (1915), Ridley (1938), Scheie and Adler (1941), Jerome and Forster (1948) who described two cases, Boyce (1951), and Smith (1954).

The optic discs were reduced in size with or without pallor in all cases, but in contradistinction to the uniocular cases there was no squint. Three patients had nystagmus. The majority were either completely blind or with vision reduced to perception of light. Schwarz (1915), however, reported a visual acuity of 6/12 in both eyes and there was binasal hemianopia, to account for which bilateral failure of development of the uncrossed fibres was postulated. In one of the cases reported by Jerome and Forster (1948), there was perception of light in the right eye, and a visual acuity of $6 / 15$ with a superior temporal field defect in the left. Smith (1954) reported a bilateral case characterized by much glial tissue on both discs, and the macular areas could not be differentiated. In the case reported by Ridley (1938), the fundi were remarkable for the deep excavation of the discs from which thread-like vessels emerged. Scheie and Adler (1941) $x$-rayed the optic foramina and found them to be of normal diameter.

Embryology of the Condition.-Scheie and Adler (1941) discussed the nature of the embryological disturbance responsible for thc condition, and distinguished between partial aplasia (or hypoplasia) and complete aplasia of the optic nerve. They believed that in partial aplasia there was a failure of development in the ganglion cells only, whereas in complete aplasia there was an additional failure of the mesodermal elements. The cause of the embryological disturbance responsible for the anomaly is not known (Mann, 1957), but a consideration of Mann's description of the normal development of the optic nerve (Mann, 1928) has suggested that it must operate in the early weeks of foetal life. Evidently the ganglion cells fail to develop from the differentiating inner neuroblastic layer of the retina at about the $17-\mathrm{mm}$. stage. As a result of this the optic stalk is subsequently deprived of the nerve fibres which would normally have grown centripetally into it through the primitive epithelial papilla, as axones derived from the ganglion cells. The optic nerve is therefore small in diameter and a mere travesty of a 
nerve, as it contains mesodermal elements only (apart from glial cells). Should there be an additional failure of mesodermal elements, complete aplasia occurs, and the optic disc and retinal blood vessels are absent. In such patients the foetal fissure has closed without trace (because nothing has been entrapped by it) at about the $13-\mathrm{mm}$. stage. Sometimes only partial failure of the mesodermal elements occurs in addition to failure of ganglion cell development, and in such patients a rudimentary disc and some retinal vessels can be seen.

Among the reported cases of aplasia occurring in otherwise normal eyes all were probably due to a failure of development of the ectodermal elements of the nerve alone, with the exception of that described by Ridley (1938), in which an additional partial failure of the mesodermal elements had presumably occurred to account for the appearance of the fundi. Retze (1901) described a comparable case, but with an additional congenital defect (microphthalmos); the optic disc, retinal vessels, and macular area could not be distinguished ophthalmoscopically in one eye, suggesting that there was complete aplasia of the corresponding optic nerve.

Aplasia associated with gross congenital abnormality, such as anencephaly and hydrocephaly (Rosenbaum, 1902), cyclopia (van Duyse, 1899), and cephalocele (Sachsalber, 1905), has frequently been described, and the condition is also well recognized in animals (Duke-Elder, 1938). Some degree of aplasia is the general rule in anencephaly (Mann, 1957). In these instances histological examination has been possible. Rosenbaum (1902) described complete uniocular aplasia in a rabbit; the ganglion cell layer, optic disc, nerve fibres, and retinal blood vessels were all absent. Zeeman and Tumbelaka (1916) reported the histological findings in a congenitally blind cat. There were no central retinal vessels, and the whole of the second neurone system of the visual pathway was missing in the animal. Szymanski (1926) described a cat with bilateral aplasia, complete in the left eye, but confined to the crossed fibres of the other eye. Vision was present in the right eye in spite of a deeply-cupped optic disc. The left eye was blind and the disc and retinal vessels could not be seen ophthalmoscopically. Histology revealed complete absence of ganglion cells and retinal nerve fibres in the left eye, whereas in the right eye they were found on the temporal side of the retina only.

\section{Conclusion}

Aplasia of the optic nerve is more readily envisaged as a developmental anomaly associated with other congenital defects, and is so seen. It may, however, occur as an isolated aberration and affect one or both nerves. When only one nerve is affected the condition may present as strabismus, and in this event the characteristic fundus appearance is likely to be the chief evidence of its presence, unless an abnormally small optic foramen can be demonstrated radiologically. 


\section{Summary}

A case of uniocular aplasia of the optic nerve is reported, and similar cases are reviewed, together with others arising bilaterally and in animals.

The clinical features and the embryology of the condition are discussed.

I am greatly indebted to Mr. H. E. Hobbs for his help, and for permission to report this case.

My thanks are due to the Radiological and Photographic Departments of the Royal Free Hospital for the skiagrams and fundus photographs.

\section{REFERENCES}

BOYCE, D. C. (1951). Amer. J. Ophthal., 34, 888.

CoRDs, R. (1923). Klin. Mbl. Augenheilk., 71, 414.

DUKE-ELDER, S. (1938). "Text-book of Ophthalmology", vol. 2, pp. 1341, 1412-1414. Kimpton, London.

Jerome, B., and Forster, H. W. (1948). Arch. Ophthal. (Chicago), 39, 669.

MANN, I. (1928). " "The Development of the Human Eye", p. 134. "University Press, Cambridge. (1957). "Developmental Abnormalities of the Eye", 2nd ed., pp. 51, 126. British Medical Association, London.

RetZe, W. (1901). Beitr. Augenheilk., 5, No. 47, p. 841.

RIDLEY, H. (1938). Brit. J. Ophthal., 22, 669.

ROSENBAUM, S. (1902). Z. Augenheilk., 7, 200.

SACHSALBer, A. (1905). I Ibid., 13, 711.

SCHEIE, H. G., and ADLER, F. H. (1941). Arch. Ophthal. (Chicago), 26, 61.

SCHWARZ, O. (1915). v. Graefes Arch. Ophthal., 90, 326.

SMith, H. E. (1954). Amer.J. Ophthal., 37, 498.

SZYMANSKI, M. (1926). Bull. Soc. franc. Ophtal., 39, 265.

WALSH, F. B. (1957). "Clinical Neuro-Ophthalmology", 2nd ed., p. 360. Williams and Wilkins, Baltimore.

VAN DUYSE (1899). Arch. Ophtal., 19, 25.

VelHaGen, C. (1930). Arch. Augenheilk., 102, 382.

ZeEman, W. P. C., and TumbelaKa, R. (1916). v. Graefes Arch. Ophthal., 91, 242. 